\begin{tabular}{c}
\hline KEMAS 13 (1) (2017) 1-6 \\
Jurnal Kesehatan Masyarakat
\end{tabular}

\title{
ANALYSIS OF MALARIA INCIDENCE IN BANYUMAS USING SPATIO- TEMPORAL APPROACH
}

\author{
Supriyanto ${ }^{1 凶}$, Nunung Nurhayati ${ }^{1}$, Dwi Sarwani Sri Rejeki ${ }^{2}$ \\ ${ }^{1}$ Mathematic Department, Faculty of Math and Sciences, Universitas Jenderal Soedirman Purwokerto \\ ${ }^{2}$ Public Health Department, Faculty of Health Science, Universitas Jenderal Soedirman Purwokerto
}

\begin{tabular}{l} 
Article Info \\
\hline Article History: \\
Submitted October 2016 \\
Accepted July 2017 \\
Published July 2017 \\
\hline Keywords: \\
spatial; temporal; malaria; \\
Moran's I; Banyumas \\
\hline DOI \\
http://dx.doi.org/10.15294/ \\
kemas.v13i1.7602
\end{tabular}

\begin{abstract}
Abstrct
Malaria still becomes a public health problem in Indonesia although has declined the last decades. The incidences of malaria in Banyumas shows unstable transmission and still risk of epidemic. Thus, the spatial and temporal distribution is required as part of efforts towards the elimination of malaria in Banyumas. Temporal spatial statistical methods is used to identify a group of malaria incidence at the district level. Purely spatial clusters of malaria incidence from 2004 to 2015 shows that the disease is not distributed randomly in the study area. A total of nine districts of high risk is determined by analysis of Moran's I. The analysis showed that by the Moran's I test, there is spatial autocorrelation found in the percentage malaria incidence from 2004 to 2015 in Banyumas. The use of the model can provide a means to detect the spatial distribution, temporal, and spatiotemporal malaria, as well as to identify areas of high risk of malaria. This research may help in prioritizing resources on high-risk areas for malaria control in the future and towards the elimination of malaria in Banyumas.
\end{abstract}

\section{Introduction}

Malaria remains a public health problem in the world, an estimated 3.4 million people at risk of malaria in 2012 (Xia, 2015). There are about 207 million cases of malaria worldwide, 627,000 malaria deaths estimated to have occurred in 2012. The Ministry of Health notes that almost all regions in Indonesia are malaria endemic area. Of the 495 districts/cities were observed, there are 424 districts / cities that became endemic malaria. It is estimated, $45 \%$ of Indonesia's population is also at risk of infected by malaria.

According to Badan Penelitian dan Pengembangan Kesehatan (2013), compared to 2007 the incidence of malaria in Indonesia in 2013 decreased by $1 \%$, from $2.9 \%$ to $1.9 \%$, although there are still some provinces and districts with high Annual Parasite Incidence (API) thereby potentially high transmission even outbreak can occur. Data show that as many as 17 of the 33 provinces that has value API $<1$ per 1000 population. Subsequently, 10 other provinces have API score between 1-5 per 1000 population. While, six other provinces, has value of API $>5$ per 1000 population, there is even a province that has a value API $>50$ per 1000 population (Badan Penelitian dan Pengembangan Kesehatan, 2013). Banyumas District is one malaria endemic districts in 
Central Java. There are still $44.4 \%$ of districts including the Moderate category Case Incidence (MCI) and the Low Case Incidence (LCI). Distribution of malaria cases in Banyumas in 2011-2013 showed cases of malaria are far away from the center of government (Purwokerto), where malaria area is an area that is still widely found forest, or yard around settlement (Rejeki, 2014).

Mapping the distribution of the disease epidemiologically is important to do, especially the spread of infectious diseases. So not only know the distribution pattern of the disease, endemic and risk factors of a disease in a regional, but also the discovery of the cause of transmission of the disease in hopes of pursuing a policy of how appropriate interventions in the termination of the chain and control transmission of malaria (Ristiyanto, 2007). Spatial-temporal epidemiology of malaria has provided a useful method for understanding the spatial and temporal patterns of malaria epidemics, assessing change and identifying areas of malaria transmission and malaria epidemic period with a higher risk at different scales. This study aims to analyze the incidence of malaria in Banyumas using spatial-temporal approach.

\section{Method}

The data used in this research was secondary data of prevalence of malaria from Banyumas Health Office in 2004 - 2015. The data was the number of occurrences of malaria cases from 27 districts in Banyumas. It was also used thematic administration maps of Banyumas. The demographic data covering population and population density obtained from the Central Statistics Agency Banyumas District.

This study used analysis method through the stages of exploration data from thematic maps, plot and the value of Moran's I to analyze the influence of the spatial (autocorrelation) (Lee, 2010; Jeremy, 2002; Mariella, 2010). The steps of the research in full as followed: we described the spread of the incidence of malaria cases, we made a map of the distribution with spatial pattern analysis software Geoda, we did mapping the incidence of malaria per year in a thematic map, we counted Moran's I, then identifying the pattern of distribution of events by Moran's I, creating and analyzing Moran's Scatterplot, and finally we tested the spatial dependencies.

\section{Result and Discussion}

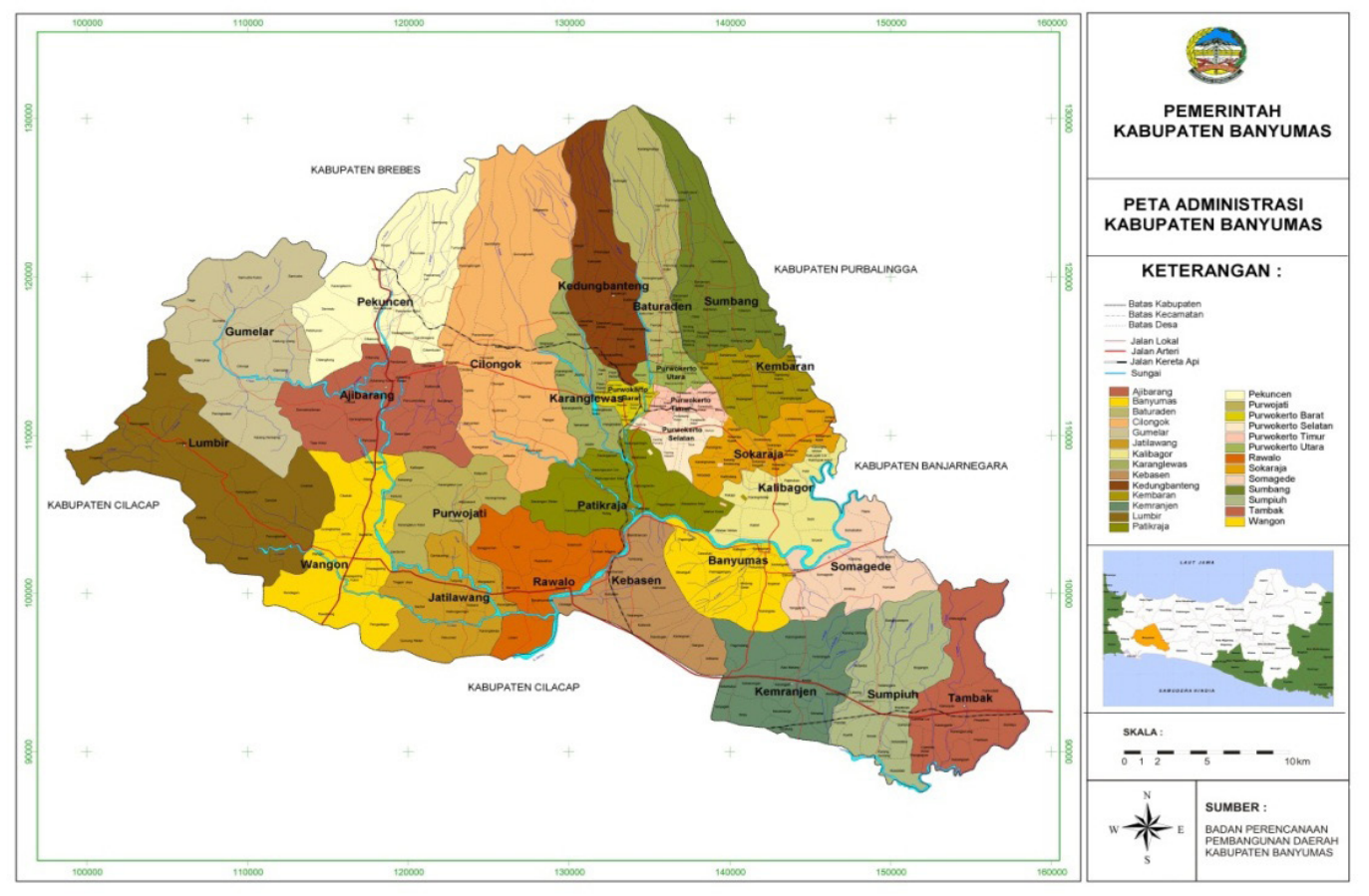

Figure 1. Map of the Banyumas district 
Banyumas is part of Central Java province. Banyumas is divided into 27 subdistrict consists of 331 villages, with an area of approximately $1327.60 \mathrm{~km}^{2}$. Geographically, Banyumas district is located between E $105^{\circ}$ and $\mathrm{E} 109^{\circ} 30$ and about $S 7^{\circ} 3$. Banyumas district borders on several districts i.e. Tegal and Pemalang (North), Cilacap (South), Cilacap and Brebes (West) and Purbalingga district, Kebumen and Banjarnegara District (East). Banyumas has a wet tropical climate with an average temperature of $26.5^{\circ} \mathrm{C}$. The minimum temperature is about $24.4^{\circ} \mathrm{C}$ and a maximum temperature is about $30.9^{\circ} \mathrm{C}$ (Rejeki et al, 2016). Here is the district of Banyumas. Of the 27 districts in Banyumas all had community health centers, there is a district that has one health center and there are two health centers, with the total number of health centers in Banyumas are 39.

In Banyumas, a total of 1899 cases of malaria have been reported from 2004 to 2015 . Figure 2 shows the annual malaria incidence from 2004 to 2015.

Figure 2 shows the malaria cases in Banyumas began an increase of cases in early 2007 to reach its peak in 2010. In 2010, an outbreak of malaria in southeast Banyumas occurred. Along with increasing time, starting in 2009 there was a decrease in cases, although still relatively high. And in 2013 till now have been fewer than 100 cases of malaria patients every year.

Measurement of spatial autocorrelation for spatial data can be calculated using the method of Moran's I. Moran's I is the method most widely used to calculate the global spatial autocorrelation. This method can be used to detect the onset of spatial randomness. This spatial randomness may indicate patterns of clustering or forming a trend towards space. According to Mariella and Tarantino (2010), the calculation of spatial autocorrelation using Moran index method. Value Moran's I and $\mathrm{Z}_{\text {count }}$ test statistic showed that in 2007, 2008, 2009, 2010, 2011, 2012, and 2013, had clustered distribution patterns. This means that the number of malaria cases among sub endemic in certain years was almost the same. Meanwhile, in the other, indicated the incidence of malaria form a pattern that spreads, which means for a particular area was quite diverse cases.

From Table 1, the result of global spatial autocorrelation analysis for the annual malaria incidence in Banyumas showed that the value of Moran's I was statistically significant for each year. This means that there has been a significant overall spatial autocorrelation.

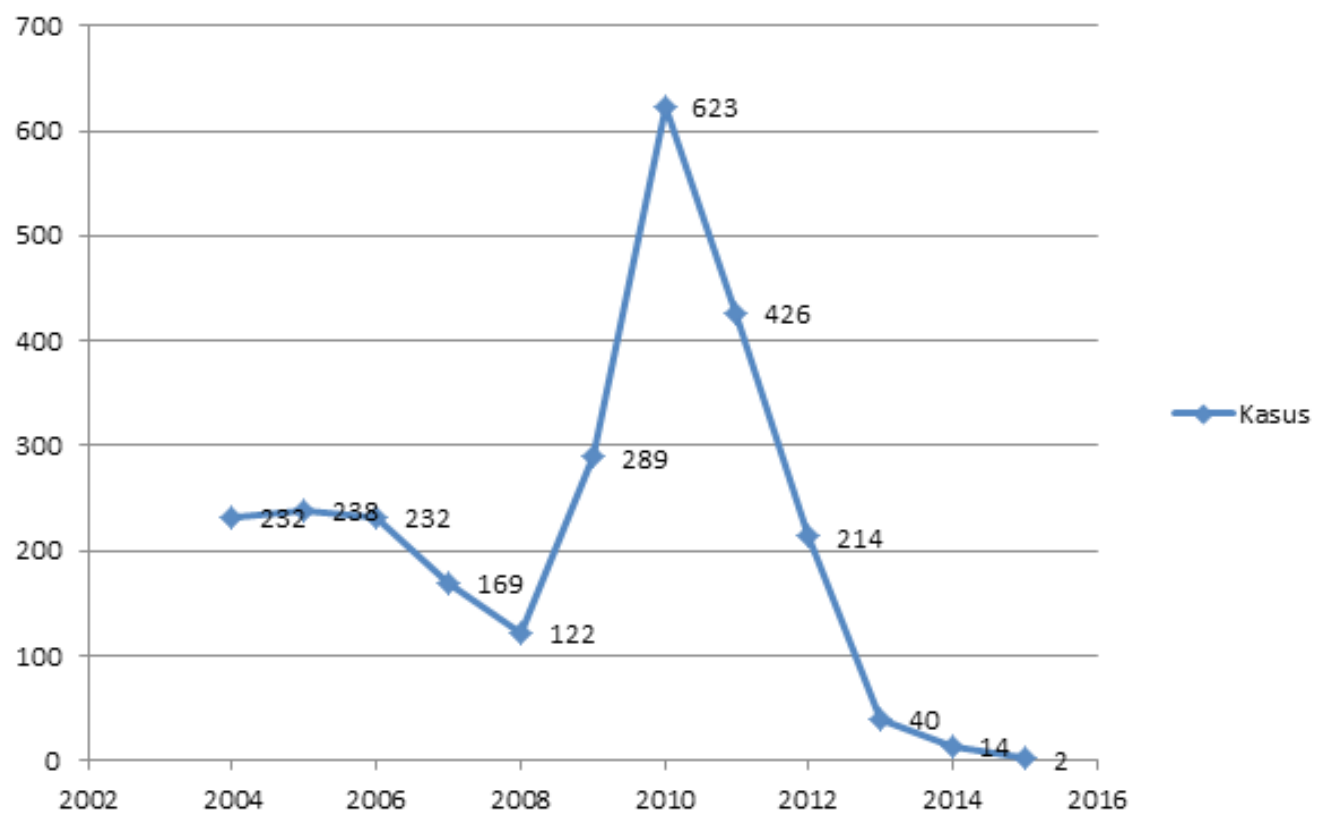

Figure 2. The number of malaria cases in Banyumas district year 2004-2015 
Table 1. Moran's I value and price expectations for malaria cases $2004-2015$

\begin{tabular}{ccc}
\hline Year & Moran's I & $\mathrm{Z}_{\text {count }}$ \\
\hline 2004 & $-0,0439$ & $-2,012$ \\
2005 & $-0,0320$ & $-1,9862$ \\
2006 & $-0,0539$ & $-3,2312$ \\
2007 & 0,4302 & 2,1341 \\
2008 & 0,5398 & 4,1290 \\
2009 & 0,3912 & 1,9982 \\
2010 & 0,1238 & 2.1765 \\
2011 & 0,3219 & 3,4976 \\
2012 & 0,5329 & 4,3981 \\
2013 & 0,2937 & 2,1092 \\
2014 & $-0,0732$ & $-1,975$ \\
2015 & $-0,1934$ & $-2,1293$ \\
\hline
\end{tabular}

Spatial cluster analysis of malaria cases 2004 - 2015 showed that malaria was not randomly distributed in the area. These results were obtained through the value of Moran's I. There were six districts with the highest cases were identified using analysis of Moran's. The incidence of malaria average annual high-risk districts was $58.81 / 100,000$ in 2010 . This value continued to decline since the year 2011 to 2015 were identified using Moran's I, the incidence of malaria median was 0.79 / 100,000 people set in 2011.

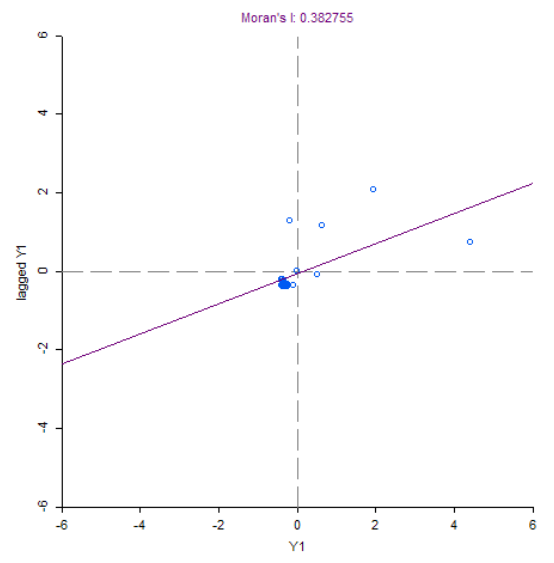

Figure 3. The value of Moran's I incidence of malaria in Banyumas

The spatial pattern of malaria role is to determine the spread of malaria incidence in a given region is consistently within a certain time. Malaria risk map that overlaid with spatial map and land cover, topographic maps as well as hydrological information will give malaria linkages with environmental variables. The linkage between the pattern of spread of malaria and environmental variables within a certain time, indicating the spread of malaria endemic area.

Spatial-temporal malaria is a method used to understand the spatial and temporal patterns of malaria epidemics, assess changes in malaria transmission and identify malariaendemic areas and time with more high risk in different scale (Alemu, 2014; Xia, 2015). Spatial-temporal analysis is used to identify the location of the cluster of high-risk areas or lowrisk malaria.

Cluster analysis of spatial indicated that the incidence of malaria decreased significantly, and the incidence of malaria average yearly of subdistricts at high risk in 2011. In 2011, three districts at high risk were identified through the analysis of Moran's I, and the spatial limits of malaria cases remained dispersed in 2011, indicates that a large population is still at risk. In this study, high-risk areas between 2007-2015 were especially in areas A, namely Sumpiuh, Tambak, Kebasen and Kemranjen subdistricts. These four regions will experience a higher incidence of malaria 44.47 times compared to endemic areas B (Sokaraja, Contribute, and Somagede districts), where endemic areas $\mathrm{B}$ will reduce local outbreak in area $\mathrm{A}$ by 28.56 times. In addition, Tambak area more frequently detected spatial cluster areas, the incidence of malaria was higher than in other districts in the epidemic area A. These results are consistent with research Rejeki, 2014 stating the subdistrict Kemranjen, Sumpiuh, Tambak, Somogede and Kebasen are subdistrict which always accounts for cases of malaria each year over the last five years (Rejeki, 2014). The community health centers that have the highest malaria cases between period 2010-2014 was Kemranjen I community health center (91 cases), Sumpiuh I community health center (491 cases), Sumpiuh II community health center (209 cases), and Tambak I community health center (272 cases) (Rejeki, 2016)

Observations in the region Somagede can be attributed to the fact that Somagede 

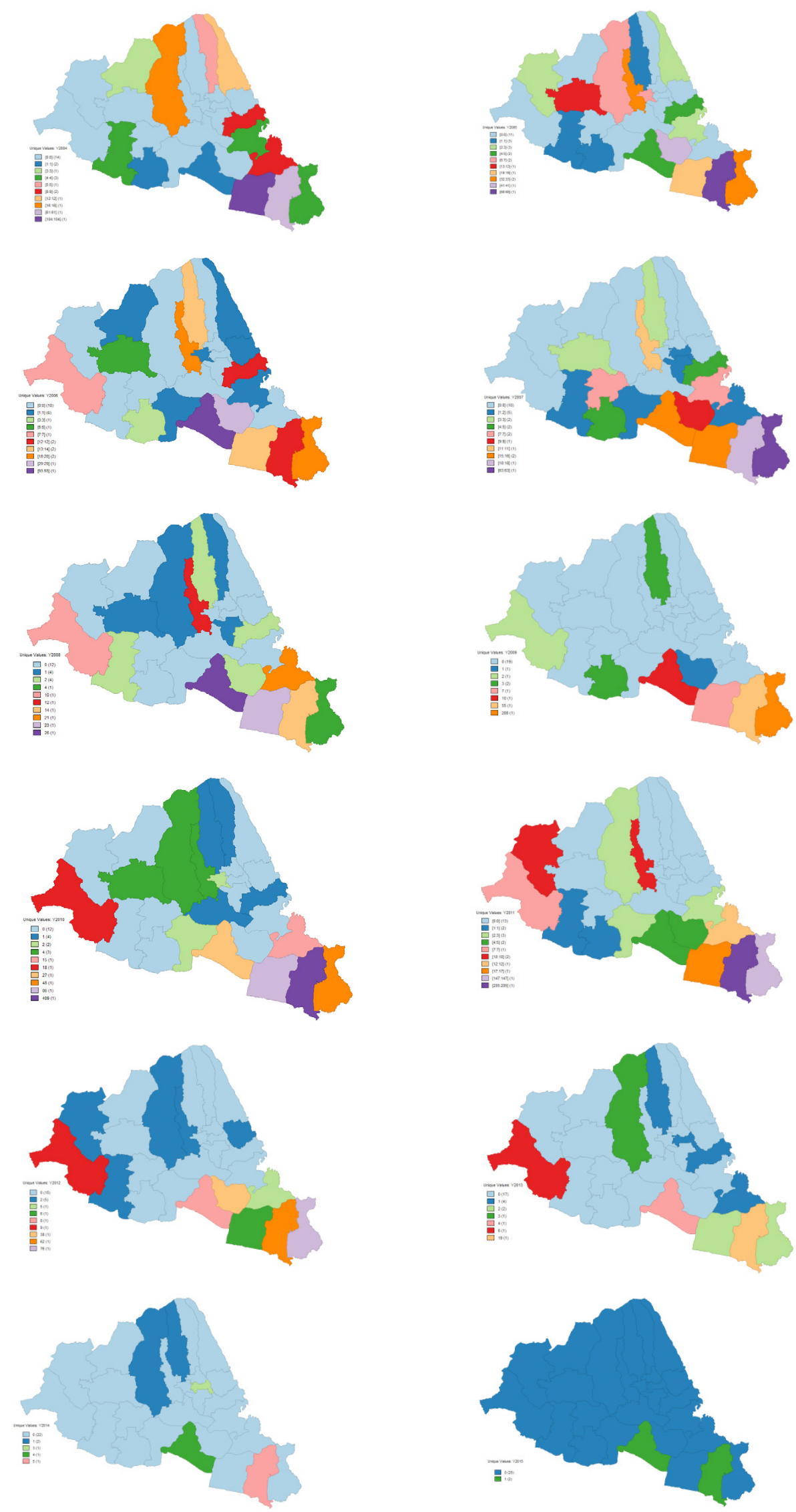

Figure 4. The pattern of the spread of malaria in Banyumas year 2004-2015 
near epidemic A. Banyumas area as high-risk areas are always focused on malaria control and elimination. Effective control strategies, such as the proper use of insecticides and environmental management, it is important for malaria vector control and should therefore be immediately implemented.

\section{Conclusion}

The incidence of malaria in Banyumas in general decreased significantly for each year to a low level from 2013 to 2015. This research can help in prioritizing the use of resources to handle cases of malaria in high-risk areas so that the malaria control would be more effective and efficient. With a prioritized resources to the troubled region is a step towards achieving the elimination of malaria in Banyumas.

\section{Acknowledgement}

Implementation of this research was funded by the Competitive Research Grant Scheme 2016, We give our greatest gratitude to the services, opportunities, and trust to LPPM Universitas Jendral Soedirman, Dean of the Faculty Math and Science, and fellow staff and lecturer of the Department of Math and Science Universitas Jenderal Soedirman.

\section{Reference}

Alemu, K., Worku, A., Berhane, Y., \& Kumie, A. 2014. Spatiotemporal Clusters of Malaria Cases at Village Level, Northwest Ethiopia. Malaria Journal, 13(1): 223

Badan penelitian dan pengembangan kesehatan
Kemenkes RI. 2013. Riset Kesehatan Dasar Jeremy, L, W. Ic., Theodore, S, R. I., Susan, S, A. H., Ranzreb. 2002. Spatial Autocorrelation and Autofegressive Models in Ecology. Ecological Monograph2, 72(3): 445-463.

Lee, L. 2010. Estimation of Spatial Autoregressive Panel Data Models with Fixed Effects. Journal of Econometrics, 154(2): 165-185

Mariella, L., \& Tarantino, M. 2010. Spatial Temporal Conditional Auto-Regressive Model: A New Autoregressive Matrix 1 Introduction. Austria Journal of Statistics, 39(3): 223-244.

Rejeki, D. S. S., Nurlaela, S., Octaviana, D., Kusnanto, H., \& Murhandarwati, E. E. H. 2016. Malaria Community Helath Workers Eliminating Malaria in Banyumas Regency. KEMAS, 12(1): 90-99.

Rejeki, D. S. S., et al. 2014. Annual Parasite Incidence Malaria di Kabupaten Banyumas. Kesmas (Jurnal Kesehatan Masyarakat Nasional), 9(2): 137-143.

Ristiyanto, Dh, F., Wahyuni, S., Gambiro, \& Sucipto. 2007. Survei dinamika penularan malaria di Desa Banjaretno, Kecamatan Kajoran, Kabupaten Magelang, Jawa Tengah. Media Litbang Kesehatan, XVII(Mci), 8 - 19. Retrieved from http://ejournal.litbang. depkes.go.id/index.php/MPK/article/ view/809/1664

Xia, J., Cai, S., Zhang, H., Lin, W., Fan, Y., Qiu, J., Nie, S. 2015. Spatial, temporal, and Spatiotemporal Analysis of Malaria in Hubei Province, China from 2004-2011. Malaria Journal, 14(1): 145 